\title{
Correlations between landscape attributes and ecological traits of Lepidoptera communities in olive groves
}

\author{
Stefano SCALERCIO ${ }^{1}$, Pietro BRANDMAYR ${ }^{3}$, Nino IANNOTTA ${ }^{1}$, Ruggero PETACCHI ${ }^{2}$ and Luigi BOCCACCiO² \\ ${ }^{1}$ CRA Centro di Ricerca per l'Olivicoltura e l'Industria Olearia, Contrada Li Rocchi, Rende, Cosenza, Italy; \\ e-mail: stefano.scalercio@entecra.it \\ ${ }^{2}$ Scuola Superiore Sant'Anna, Piazza Martiri della Libertà 33, Pisa, Italy \\ ${ }^{3}$ Università della Calabria, Via Pietro Bucci, Rende, Cosenza, Italy
}

Key words. Landscape ecology, Lepidoptera, biodiversity, ecological traits, conservation

\begin{abstract}
The effects of landscape attributes on Lepidoptera communities were studied in an agricultural area in Calabria (S-Italy). The association between a set of community descriptors and landscape metrics was determined using a multi-scale approach. Lepidoptera were sampled using yellow sticky traps in 10 olive groves. The landscape in 5 concentric areas, with radii from 250 to 1250 $\mathrm{m}$, around each sampling site was analyzed. The composition and configuration of the landscape were calculated both at the landscape and class level based on the main classes of land use. The following life-history traits of Lepidoptera were considered: (i) dispersal ability of adults, (ii) habitat preferences and (iii) diet breadth of larvae. An index of community vulnerability was calculated by combining life-history traits and species diversity. There were no significant correlations between any of the landscape metrics and species richness or between species richness and abundance of natural or semi-natural habitats. However, life-history traits were significantly correlated with some landscape metrics, depending on the spatial scale. Most notably, landscape diversity is positively correlated with community vulnerability. The presence of sensitive species in olive orchards, but not species richness per se, is associated with the presence of natural and semi-natural habitats in the surrounding agricultural landscape. In conclusion, responses of communities to landscape changes are more likely to be revealed by an analysis of ecological traits, than species richness. In particular, the vulnerability index, used in this joint analysis of the main ecological traits, seems to be an effective descriptor of the relationships between communities and landscape.
\end{abstract}

\section{INTRODUCTION}

A general trend in biotic communities is an increase in generalist species and decline in specialist species associated with both climate and land use changes (Warren et al., 2001; Julliard et al., 2003). The decline in specialists associated with human activities is recorded for ecosystems, from boreal forests (Carlson, 2000) to coral reefs (Munday, 2004). Negative effects of habitat modification on specialist species in particular are recorded in many different groups of animals ranging from birds (Devictor et al., 2008) to reptiles (Hawlena \& Bouskila, 2006). The decline in specialists and increase in the relative abundance of generalist species in response to habitat loss and fragmentation is well documented by the results of longterm studies on butterfly communities (van Swaay et al., 2006; Polus et al., 2007).

Community response to human-driven habitat change is of primary interest in agro-ecological studies, as agricultural land makes up approximately $38 \%$ of total land area (FAOSTAT Land Use Database, 2007) and biodiversity conservation and healthy ecosystem functioning are crucial factors supporting food production (Bullock et al., 2001; Brussaard et al., 2007; Fiedler et al., 2008). Biodiversity in agro-ecosystems can be increased both by reducing the level of agrochemical inputs, e.g. by organic farming (Holzschuh et al., 2008), or by improving landscape structure (Hunter, 2002) and composition (Benton et al., 2003). Several studies suggest that landscape characteristics can be as important as management in promoting farmland biodiversity (Clough et al., 2005; Rundlöf \& Smith, 2006). In particular, perennial vegetation such as woodland, grassland and boundaries of fields provide refuges during adverse seasons or pesticide applications and alternative trophic sources sustaining farmland biodiversity throughout the year (Altieri, 1999; Tscharntke et al., 2005). The creation of non-farmed habitats within agricultural landscapes is promoted by some policy measures, such as the agri-environment measures in the European Union (Musters et al., 2009). Significant effects of landscape characteristics on the distribution and movement of Lepidoptera are reported in the literature (Roland et al., 2000; Mennechez et al., 2003; Bergman et al., 2004; Dover \& Settele, 2009).

Diversity (i.e. species richness and evenness) per se is not the only parameter worthy of consideration when evaluating the health of an ecosystem or the conservation interest of an area. In some cases, diversity can be higher in human-altered landscapes than in natural landscapes (Naveh \& Whittaker, 1980). For example, butterfly diversity can be lower in natural but relatively homogeneous landscapes than in certain human-dominated landscapes containing a high availability of adult food sources. However, this pattern may be largely due to an increase in generalist and highly mobile species (Scalercio et al., 2007a). Vargas et al. (2004) found that Heteroptera spe- 
cies richness is positively correlated with human disturbance, while this is not the case if only endemic species are considered. Life history traits of species are increasingly being used in studies in ecology and conservation. In particular, using this approach it is possible to compare data collected in areas in different biogeographical regions occupied by different species.

The main ecological traits of Lepidoptera that determine their vulnerability are (Pollard \& Yates, 1993; Shreeve et al., 2001; Franzén \& Johannesson, 2007; Tscharntke et al., 2008; Barbaro \& van Halder, 2009):

(i) mobility of adult and/or larval stages, i.e. their ability to leave a habitat that is deteriorating and (re)colonise suitable sites; as a consequence, community composition in changing environments shifts towards species with a high dispersal ability (Scalercio et al., 2007a, b; Warren et al., 2001);

(ii) habitat range, i.e. their ability to colonise other habitats when the preferred one becomes unsuitable;

(iii) diet breadth of larvae, i.e. their ability to complete their development on a wide range of host plant species.

As a result, the less mobile and the more specialised the species in a particular community the more vulnerable it is to extinction. Scalercio et al. (2007a) integrated this information, along with that originating from a diversity analysis, to define a vulnerability index, which was used to rank landscape patches in terms of their sensitivity to habitat alteration.

In order to assess the suitability of a landscape for species that score unfavourably in terms of the abovementioned life-history traits, it is important to analyse how particular species traits are associated with landscape and other abiotic variables (Krauss et al., 2003; Summerville \& Crist, 2004; Thuiller et al., 2005). A number of studies demonstrate that fragmentation of natural and semi-natural habitats endanger threatened animals, including Lepidoptera (Schtickzelle et al., 2006), and the occurrence of animals with particular life-history traits is strongly associated with particular landscape characteristics (Shreeve et al., 2001; Tscharntke et al., 2008).

The association of particular species traits of insects with landscape characteristics depends on the spatial scale at which a landscape is analyzed (Roschewitz et al., 2005) because the species differ in their dispersal ability or foraging ranges (Westphal et al., 2006). Multiscale analyses, carried out simultaneously on the same data at different spatial scales, taking into account the seasonality of the target group, provide a means of determining the association between landscape ecology and biodiversity of insects (Rossi \& van Halder, 2010). GIS-based landscape analysis and calculation of landscape metrics is widely used in ecological studies of insects (Thies et al., 2003; Diekötter et al., 2008; Zaller et al., 2008; Boccaccio \& Petacchi, 2009) and Lepidoptera in particular (Bergman et al., 2004; Rundlöf \& Smith, 2006) in agricultural landscapes.

In this paper a multiscale approach was used to determine the ecological traits of Lepidoptera sampled in human-altered agricultural systems of olive groves that

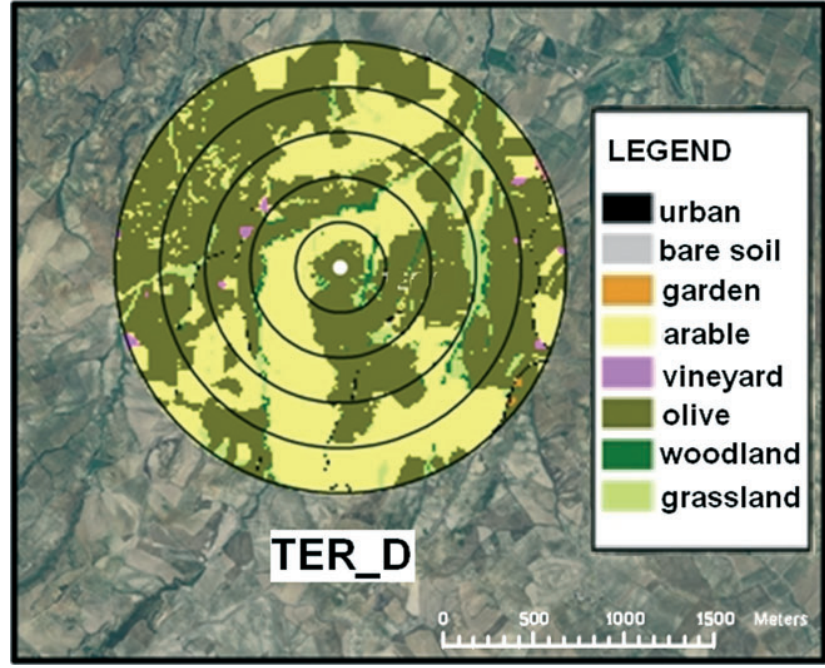

Fig. 1. Aerial photograph of the landscape surrounding sampling site (TER_D) showing the 5 concentric spatial zones with

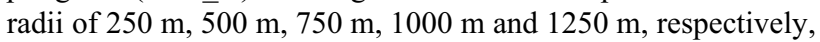
in which the structure of the landscape was analysed. Digitisation was performed using a vector grid of $15 \mathrm{~m} \times 15 \mathrm{~m}$.

are associated with attributes of the landscape surrounding the sampling sites at different spatial scales. We assessed which landscape characteristics are positively associated with the persistence of vulnerable species. We also asked how, and at what spatial scale, landscape composition affects the quality of lepidopteran communities, highlighting the contribution of non-farmed habitats and using a range of descriptors of lepidopteran communities, including abundance, diversity, specific life-history traits and a community vulnerability index, which includes information on diversity, mobility and habitat selectivity.

\section{MATERIAL AND METHODS}

Samples of Lepidoptera were collected from 10 olive groves located in northern Calabria, Italy. Three are located in the municipality of Mirto-Crosia (MIR_A, MIR_B, MIR_C), four in Terranova da Sibari (TER_A, TER_B, TER_C, TER_D) and three in Rende (ARC_A, ARC_B and LIR_A). These sites reflect the existing diversity of landscapes in this area.

A geographic information database was built upon orthorectified aerial photographs (year 2007, spatial resolution of 0.5 $\mathrm{m} \times 0.5 \mathrm{~m}$ ) using ArcGIS 8 software (ESRI, 2003). The landscape pattern was digitised on a vector grid of $15 \times 15 \mathrm{~m}$. After preliminary trials, this grid size was chosen in order to reflect the integrity of olive cropping units. The following classes of land cover were identified: (I) water bodies, (II) urban, (III) bare soil and rocks, (IV) gardens, (V) arable land, (VI) vineyards, (VII) olive groves, (VIII) citrus groves, (IX) other tree plantations, (X) woodland (including both forest and maquis), (XI) permanent grassland.

Vector land cover maps were converted into raster format at 5 concentric spatial scales, with radii of $0.25 \mathrm{~km}, 0.50 \mathrm{~km}, 0.75$ $\mathrm{km}, 1.00 \mathrm{~km}$ and $1.25 \mathrm{~km}$, around a geo-reference point located in the centre of each sampled olive grove (Fig. 1). The maximum radius covers the home range of most Lepidoptera species present in the study area, as dispersal beyond $1 \mathrm{~km}$ is relatively uncommon (Thomas et al., 1998). Other spatial scales were included in the analysis in order to evaluate at which spa- 
TABLE 1. Number of traps operated at each sampling site, description of the landscape and associated communities of Lepidoptera. Landscape data is for the area within a radius of $1000 \mathrm{~m}$ of the sites sampled. $S$ - species richness and N - number of individuals (both compared after 100 randomisations performed by running EstimateS 7.5 (Colwell, 2005) and using the cumulated number collected in the first four samples); $I_{\mathrm{v}}$ - vulnerability index; PARA_AM - Perimeter-area ratio area-weighted mean; SHDI Shannon's index of landscape diversity.

\begin{tabular}{lcccccccc}
\hline Sampling site & $\begin{array}{c}\text { Traps } \\
\left(\mathrm{N}^{\circ}\right)\end{array}$ & $S$ & $N$ & $I_{\mathrm{v}}$ & PARA_AM & SHDI & \multicolumn{2}{c}{ Percentage of landscape (\%) } \\
\cline { 7 - 9 } & 11 & 14.58 & 10.73 & -0.226 & 886.92 & 1.74 & 22.17 & 12.77 \\
ARC A & 6 & 31.47 & 23.83 & 0.024 & 808.23 & 1.67 & 26.55 & 12.81 \\
ARC B & 17 & 16.35 & 10.18 & 0.078 & 904.27 & 1.68 & 6.65 & 11.19 \\
LIR A & 7 & 21.03 & 21.86 & -0.089 & 469.43 & 1.68 & 0.17 & 0.77 \\
MIR A & 8 & 19.20 & 13.88 & -0.070 & 475.92 & 1.70 & 0.17 & 0.84 \\
MIR B & 10 & 12.86 & 13.30 & -0.317 & 641.92 & 2.02 & 0.66 & 3.35 \\
MIR C & 14 & 15.19 & 13.14 & -0.479 & 332.80 & 1.20 & 0.18 & 2.01 \\
TER A & 19 & 18.19 & 15.16 & -0.283 & 392.53 & 1.40 & 1.27 & 3.69 \\
TER B & 18 & 18.12 & 13.50 & -0.215 & 436.45 & 1.47 & 1.92 & 4.26 \\
TER C & 4 & 13.00 & 12.75 & -0.471 & 391.35 & 0.99 & 2.21 & 5.97 \\
TER D & & & & & & & & Grassland \\
\hline
\end{tabular}

tial scale the selected ecological traits of Lepidoptera are most strongly associated with landscape attributes.

Spatial scales were analysed using FRAGSTATS 3.3 software (McGarigal et al., 2002) and the 8-neighbour rule for calculating metrics. The landscape metrics listed below were chosen, as these variables are known to be associated with communities of Lepidoptera (Usher \& Keiller, 1998):

\section{Class-level metrics}

Percentage of landscape (PLAND) composed of a particular type of land use (woodlands, grasslands, annual crops). The percentage of landscape reflects the abundance of a given type of land use in the landscape and is widely used as the most intuitive descriptor of landscape composition in landscape-based entomological studies (Kruess, 2003; Jackson et al., 2007). It is calculated using the following formula, where $a_{i}$ is the area of a patch of a particular type of land use and $A$ is the total landscape area.

$$
P L A N D=100 *\left(\Sigma_{i} a_{i}\right) / A
$$

Landscape level metrics

Perimeter-area ratio, area-weighted mean (PARA AM), equals the ratio of the patch perimeter $\left(p_{i}\right)$ to area $\left(a_{i}\right)$, calculated across all patches ${ }_{i}$ ) of a given landscape type and expressed as an area-weighted mean. This metric reflects the complexity of the shape of parches of particular types of land use and therefore is a means of quantifying the edge effect (Collinge \& Palmer, 2002).

$$
P A R A \_A M=\Sigma_{i}\left(p_{i} / a_{i}\right) *\left(a_{i} / \Sigma_{i} a_{i}\right)
$$

Shannon's index of landscape diversity $(S H D I)$ quantifies the diversity of a given landscape based on two components: the number of different land use classes (richness) and the proportional area distribution among classes (evenness). SHDI is calculated by adding, for each class of land use present in the landscape, the proportion of area $\left(P_{i}\right)$ covered by the class itself, multiplied by that same proportion expressed in natural logarithm $\left(\ln P_{i}\right)$ (Krauss et al., 2004).

$$
S H D I=-\Sigma_{i}\left(P_{i} * \ln P_{i}\right)
$$

\section{Entomological samples}

Lepidoptera included belong to the super-families Hesperioidea, Papilionoidea, Noctuoidea and Geometroidea. Ecology of species belonging to these super-families is sufficiently, but not exhaustively, known. Microlepidoptera were not included in this study because of they are difficult to handle /identify and their life histories are largely unknown.

Sampling was undertaken in 2005 and 2006. Lepidoptera were caught using 115 yellow sticky plastic traps $(17 \times 25 \times 0.3$ $\mathrm{cm})$ positioned $150 \mathrm{~cm}$ above the soil, close to the canopies of olive trees. The yellow traps were each immersed in a solution of commercial synthetic rat glue and petrol ether prior to use in the field and replaced every ten days from mid-June to early December, that is, over a continuous period of 6 months. A different number of traps were set at each study site, ranging from 4 to 19 (Table 1). Traps were located around the barycentre of each study site at a distance of $20 \mathrm{~m}$ from each other. Species were counted and identified in the laboratory.

Although yellow sticky traps are not very attractive for Lepidoptera, their use has the advantage that they are not more or less attractive to butterflies or moths and thus provide a sample of all the taxa present in an area using a single sampling method. However, yellow may be more attractive for specific species as it is reported for Lepidoptera caught by pan-traps (Benes et al., 2000).

\section{Data analysis}

As the sampling effort was not uniform, i.e. different numbers of traps were used at each study site, species richness and abundance were compared after 100 randomisations using EstimateS 7.5 (Colwell, 2005). The cumulative number of species and individuals in the first four samples were used in the subsequent analyses as this is the maximum number of samples available for each site sampled.

The quality and vulnerability of Lepidoptera communities at each site sampled was quantified using the following measures (Scalercio et al., 2007a):

- Shannon's index of diversity $\left(H^{\prime}\right)$, using natural logarithm;

- Mobility $(M)$, computed by summing, for each species $(i)$, the product of the proportion of individuals $\left(\mathrm{p}_{\mathrm{i}}\right)$ in the community made up of that species and its mobility range $\left(M R_{i}\right)$

$$
M=\Sigma_{i}\left(p_{i} M R_{i}\right) \text {. }
$$

- Eurytopy $(E)$, i.e. the ability to tolerate a wide range of habitats, calculated by summing the proportion of individuals $\left(P_{e}\right)$ of each eurytopic species $(e)$ across the community

$$
E=\Sigma_{e} P_{e}
$$

- The community vulnerability index $\left(I_{\mathrm{v}}\right)$ was computed according to the following equation:

$$
I_{\mathrm{v}}=\left(H^{\prime} / M\right)-2 E
$$


TABLE 2. Mean number of species $(S)$ and individuals $(N)$ collected per trap \pm SD classified according to their dispersal ability (low, medium, high), habitat preference (W - woodland, E - ecotone, G - grassland, Gen - generalist) and host-plant specificity (mon monophagous, oli - oligophagous, pol - polyphagous).

\begin{tabular}{|c|c|c|c|c|c|c|c|c|c|c|c|}
\hline \multirow{2}{*}{ Site } & & \multicolumn{3}{|c|}{ Dispersal power } & \multicolumn{4}{|c|}{ Habitat preference } & \multicolumn{3}{|c|}{ Host-plant specificity } \\
\hline & & low & medium & high & W & E & $\mathrm{G}$ & Gen & mon & oli & pol \\
\hline \multirow[t]{2}{*}{ ARC_A } & $S$ & $0.73 \pm 0.65$ & $1.82 \pm 0.98$ & $2.82 \pm 1.47$ & $36 \pm 0.51$ & $0.91 \pm 0.94$ & $1.18 \pm 0.60$ & $3.00 \pm 1.67$ & $0.09 \pm 0.30$ & $4.09 \pm 1.58$ & $1.27 \pm 0.79$ \\
\hline & $N$ & $0.82 \pm 0.75$ & $5.64 \pm 2.66$ & $4.27 \pm 3.69$ & $0.36 \pm 0.51$ & $1.00 \pm 1.09$ & $4.82 \pm 2.96$ & $4.55 \pm 3.70$ & $0.09 \pm 0.30$ & $9.27 \pm 5.52$ & $1.36 \pm 0.81$ \\
\hline \multirow[t]{2}{*}{ ARC_B } & $S$ & $2.17 \pm 1.60$ & $4.50 \pm 1.64$ & $4.83 \pm 2.04$ & $1.67 \pm 1.37$ & $3.17 \pm 1.47$ & $1.83 \pm 0.75$ & $4.83 \pm 2.71$ & $0.50 \pm 0.55$ & $6.67 \pm 2.16$ & $4.50 \pm 1.15$ \\
\hline & $N$ & $2.67 \pm 1.63$ & $13.33 \pm 7.49$ & $7.83 \pm 2.56$ & $2.17 \pm 1.94$ & $4.33 \pm 2.81$ & $33 \pm 7.45$ & $8.00 \pm 3.69$ & $0.67 \pm 0.82$ & $17.33 \pm 8.38$ & $3 \pm 4.40$ \\
\hline \multirow[t]{2}{*}{ LIR_A } & $S$ & $0.94 \pm 1.20$ & $2.77 \pm 0$. & $2.41 \pm 1.00$ & & $1.41 \pm 1.06$ & $9 \pm 0.62$ & & $24 \pm 0.44$ & & \\
\hline & $N$ & $1.00 \pm 1.28$ & $6.06 \pm 2.97$ & $3.18 \pm$ & 72 & $1.47 \pm 1$ & $4.77 \pm 2.73$ & $3.35=$ & $.24 \pm 0.44$ & 40 & $1.00 \pm 1.2$ \\
\hline \multirow[t]{2}{*}{ MIR_A } & $S$ & $1.14 \pm 0.90$ & $4.00 \pm 1.29$ & $3.43 \pm 1.51$ & $0.71 \pm 0.95$ & $1.71 \pm 0.76$ & $2.57 \pm 1.27$ & $3.57 \pm 1.27$ & $0.57 \pm 0.79$ & $5.57 \pm 1.62$ & $2.43 \pm 1.40$ \\
\hline & $N$ & $1.71 \pm 1.50$ & $12.57 \pm 5.03$ & $7.57 \pm 3.60$ & $1.29 \pm 1.70$ & $2.71 \pm 2.14$ & $9.57 \pm 4.61$ & $8.29 \pm 4.46$ & $0.57 \pm 0.79$ & $17.86 \pm$ & $3.43 \pm 1.9$ \\
\hline \multirow[t]{2}{*}{ MIR_B } & $S$ & $1.14 \pm 1.07$ & $3.50 \pm 1.20$ & $3.50 \pm 1.69$ & $0.38 \pm 0.52$ & $2.25 \pm 1.04$ & $2.13 \pm 0.84$ & $3.25 \pm 1.39$ & $0.38 \pm 0.74$ & $5.75 \pm 1.83$ & $1.88 \pm 0.8$ \\
\hline & $N$ & $1.29 \pm 1.25$ & $6.63 \pm 2.20$ & $6.00 \pm 3.12$ & $0.50 \pm 0.76$ & $2.88 \pm 1.46$ & $4.88 \pm 1.73$ & $5.75 \pm$ & $0.38 \pm 0.74$ & .45 & $3.25 \pm 1.9$ \\
\hline \multirow[t]{2}{*}{ MIR_C } & $S$ & $0.70 \pm 0.68$ & $2.40 \pm 0.97$ & $2.20 \pm 1.32$ & $0.40 \pm 0.52$ & $1.80 \pm 1.03$ & $1.40 \pm 0.70$ & $1.70 \pm 0.82$ & $0.10 \pm 0.32$ & $3.30 \pm 0.95$ & $1.90 \pm 1.10$ \\
\hline & $N$ & $0.70 \pm 0.68$ & $6.40 \pm 4.09$ & $6.20 \pm 4.67$ & $0.40 \pm 0.52$ & $3.80 \pm 2.82$ & $3.50 \pm 1.78$ & $5.70 \pm 4.52$ & $0.10 \pm 0.32$ & $9.20 \pm 3.52$ & $4.00 \pm 2.54$ \\
\hline \multirow[t]{2}{*}{ TER_A } & $S$ & $0.79 \pm 0.80$ & $2.21 \pm 1.25$ & $3.07 \pm 1.00$ & $0.29 \pm 0.47$ & $1.29 \pm 0.99$ & $1.43 \pm 0.65$ & $3.07 \pm 1.00$ & $0.21 \pm 0.43$ & $4.07 \pm 1.21$ & $1.71 \pm 1.14$ \\
\hline & $N$ & $0.86 \pm 0.95$ & $5.43 \pm 3.30$ & $6.86 \pm 4.99$ & $0.36 \pm 0.63$ & $1.36 \pm 1.15$ & $4.43 \pm 3.18$ & $7.00 \pm 4.84$ & $0.21 \pm 0.43$ & $10.21 \pm 5.87$ & $2.57 \pm 3.50$ \\
\hline \multirow[t]{2}{*}{ TER_B } & $S$ & $0.63 \pm 0.76$ & $3.11 \pm 1.05$ & $3.74 \pm 1.45$ & $0.53 \pm 0.70$ & $1.26 \pm 1.24$ & $2.00 \pm 0.75$ & $3.68 \pm 1.60$ & $0.16 \pm 0.38$ & $5.16 \pm 1.74$ & $2.11 \pm 1.60$ \\
\hline & $N$ & $0.63 \pm 0.76$ & $6.53 \pm 3.75$ & $8.00 \pm 4.81$ & $0.53 \pm 0.70$ & $1.74 \pm 2.00$ & $5.63 \pm 3.72$ & $7.26 \pm 5.51$ & $0.16 \pm 0.38$ & $11.16 \pm 7.74$ & $3.79 \pm 3.52$ \\
\hline \multirow[t]{2}{*}{ TER_C } & $S$ & $0.50 \pm 0.79$ & $3.17 \pm 1.38$ & $3.72 \pm 1.27$ & $0.50 \pm 0.51$ & $1.67 \pm 1.03$ & $1.78 \pm 0.73$ & $3.56 \pm 1.34$ & $0.22 \pm 0.43$ & $5.06 \pm 1.59$ & $2.11 \pm 1.08$ \\
\hline & $N$ & $0.61 \pm 0.92$ & $6.39 \pm 3.79$ & $6.33 \pm 3.65$ & $0.56 \pm 0.62$ & $1.83 \pm 1.34$ & $4.83 \pm 3.63$ & $6.11 \pm 4.00$ & $0.28 \pm 0.58$ & $10.56 \pm 6.50$ & $2.50 \pm 1.34$ \\
\hline \multirow[t]{2}{*}{ TER_D } & $S$ & $1.75 \pm 0.50$ & $2.00 \pm 0.00$ & $2.50 \pm 0.58$ & $0.00 \pm 0.00$ & $1.75 \pm 0.50$ & $2.25 \pm 0.96$ & $2.50 \pm 0.58$ & $0.25 \pm 0.50$ & $4.00 \pm 0.82$ & $2.25 \pm 0.96$ \\
\hline & $N$ & $1.75 \pm 0.50$ & $4.00 \pm 2.45$ & $7.0 \pm 4.08$ & $0.00 \pm 0.00$ & $1.75 \pm 0.50$ & $4.25 \pm 3.30$ & $6.75 \pm 3.80$ & $0.25 \pm 0.50$ & $8.00 \pm 3.65$ & $4.50 \pm 3.11$ \\
\hline
\end{tabular}

where:

$H^{\prime}=$ Shannon's index of the species assemblage;

$M=$ mobility of the species assemblage;

$E=$ eurytopy of the species assemblage.

Shannon's index was selected as a measure of diversity as it is widely used in ecological studies (Grill et al., 2005; Simon et al., 2007) and not very sensitive to rare species and sample size (Magurran, 1988). Mobility ranges and fundamental ecological categories proposed by Balletto \& Kudrna (1985) were used in the calculations. Mobility range varies from 1 for sedentary species to 5 for migratory species. Because the level of knowledge of moths is less than that of butterflies only three mobility ranges were used for the former: 1 for sedentary, 5 for migratory and 3 for other species. Eurytopic species are those reported in a wide range of habitats.

Furthermore, for each site sampled, we computed the average abundance and richness, per trap, of species belonging to the following ecological groups (based on information in several papers and books, preferentially those on Mediterranean fauna (Balletto \& Kudrna, 1985; Berio, 1985, 1991; Parenzan, 1994; Bertaccini et al., 1995, 1997; Hausmann, 2001, 2004; Mironov, 2003 and literature therein): (i) grassland species, those occurring in habitats dominated by herbaceous vegetation; (ii) woodland species, occurring mainly in forests; (iii) ecotonal species, clearings and forest margins; and (iv) generalist species, in a wide range of habitats in Mediterranean countries.

Depending on their powers of dispersal, species were categorised as follows: (a) high dispersal frequency, those that are able to rapidly respond to environmental changes by migrating; (b) medium dispersal frequency, those that are able to respond to environmental changes but more slowly than those included in the previous category and only if a suitable habitat is close by; (c) low dispersal frequency, those that are able only to escape small and temporally limited environmental changes, usually only dispersing hundreds of meters during their lifetime. Although five ranges of the mobility index are used only three categories were used in this study because there is less detailed information on moths than on butterflies, for which five categories can be discriminated. Species with a low dispersal frequency are those with a mobility range of 1 , those with a high dispersal frequency have a mobility range of 5 and those with a medium dispersal frequency a range of from 2 to 4 .

Based on the host-plant specificity of the larvae the species were designated either as: (1) monophagous, species whose larvae feed on plants belonging to one species or genus; (2) oligophagous, with larvae feeding on plant species belonging to at least two genera, but no more than one family; (3) polyphagous species, whose larvae feed on plant species belonging to at least two families.

Linear correlations between the following indices: species richness, abundance, vulnerability, dispersal ability, habitat preference and host-plant specificity, and landscape attributes (percentage of woodland, grassland and arable land), Shannon's landscape diversity index and Perimeter-area ratio, and the computation of mean values and their standard deviations were calculated using Statistica 5.5 (StatSoft).

\section{RESULTS}

\section{Landscape analysis}

Of the landscape-level metrics, the perimeter-area ratio recorded at the different sites sampled varied considerably whereas the Shannon's diversity index was quite homogeneous and relatively low. The abundance of natural and semi-natural habitats was extremely low in 
most of the landscapes analyzed (Table 1). In fact, the dominant type of land use around the plots sampled was agricultural. Both the landscape-level and class-level metrics indicate that the landscape in the area studied was relatively simple and unlikely to sustain many species of Lepidoptera.

\section{Structure of the Lepidopteran community}

We collected 1,577 individuals belonging to 95 species (Appendix 1). The most abundant families were Nymphalidae $(N=580)$ and Pieridae $(N=463)$, the most specious families were Noctuidae $(S=35)$ and Geometridae $(S=24)$. Lasiommata megera and Pieris brassicae were the most abundant species and made up half of all the individuals sampled.

Species richness was relatively low at all the sites sampled, ranging between 12.9 (MIR_C) and 31.5 (ARC_B) species recorded up to the fourth sample. This reflects the simple nature of the landscape and low ecological quality of the dominant habitats (Table 1).

The negative values for the community vulnerability index recorded in this study are typical of human-altered habitats. Only two communities had positive, but very low, values (Table 1). Abundance of the species was also generally low as was species richness. No more than 23.8 individuals per trap were collected over the whole sampling period (Table 1). Species with medium or high dispersal ability dominated the samples, together with habitat generalists and oligophagous species. Poor dispersers, monophagous species and woodland species were scarcely represented (Table 2).

Associations between Lepidoptera and various attributes of the landscape

Species richness and abundance did not correlate with any of landscape metrics recorded, while other species traits correlated with a few attributes. The mean number of woodland individuals significantly correlated with the percentage of woodland, but only at the larger spatial scale $(1000 \mathrm{~m})$. Conversely, species with low dispersal ability were strongly associated with the percentage of the landscape under grassland, but only at a small spatial scale $(250 \mathrm{~m})$ (Table 3$)$.

The community vulnerability index was associated much more closely with landscape attributes than abundance and species richness. It is positively correlated with the Shannon's diversity index and the perimeter-area ratio measured within $1000 \mathrm{~m}$ (Table 3).

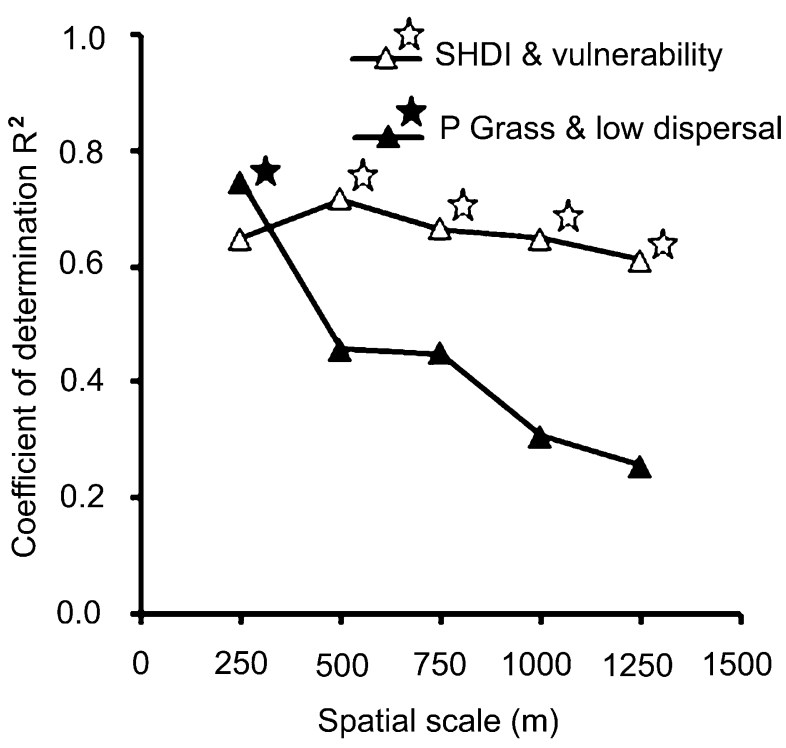

Fig. 2. The coefficients of determination of the regressions at different spatial scales of the community vulnerability index on Shannon's index of landscape diversity (SHDI \& vulnerability) and number of individuals with low dispersal ability on percentage of the landscape under grassland (P Grass \& low dispersal). Explanatory power of the regressions is expressed in terms of the coefficient of determination $\mathrm{R}^{2}$. Stars indicate statistically significant linear correlations $(\mathrm{p}<0.05)$.

The predictive power of landscape metrics as community descriptors is quantified by the coefficient of determination $R^{2}$. This varied depending on the spatial scale at which the landscape surrounding the focal points was analyzed. Shannon's index of landscape diversity was most strongly associated with community vulnerability measured within $500 \mathrm{~m}$ of the focal points and decreased thereafter. The power of the percentage of the landscape occupied by grassland for predicting the abundance of Lepidoptera with poor dispersal ability decreased with increasing spatial scale. On average, $R^{2}$ values were higher for the vulnerability index than for dispersal ability (Fig. 2).

\section{DISCUSSION AND CONCLUSIONS}

The main finding of this paper is that heterogeneous landscapes with remnants of wild vegetation are important for sustaining species that are sensitive to alterations to their habitats, while natural and semi-natural habitats have only a marginal role in sustaining species richness

TABLE 3. Correlations between ecological traits of Lepidoptera and landscape metrics at different spatial scales, for both species and individuals (the last in parentheses).

\begin{tabular}{lcccccc}
\hline \multirow{2}{*}{ Landscape metrics } & Community & \multicolumn{4}{c}{ Buffer radius $(\mathrm{m})$} \\
\cline { 3 - 7 } & attributes & 250 & 500 & 750 & 1000 & 1250 \\
\hline Percentage of woodland & Woodland species & $0.13(0.20)$ & $0.28(0.38)$ & $0.41(0.51)$ & $0.55\left(0.64^{*}\right)$ & $0.48(0.58)$ \\
Percentage of grassland & Low dispersal species & $0.75^{*}\left(0.77^{* *}\right)$ & $0.47(0.45)$ & $0.44(0.42)$ & $0.34(0.29)$ & $0.27(0.24)$ \\
Shannon's landscape diversity index & Vulnerability index & 0.53 & $0.77^{* *}$ & $0.69^{*}$ & $0.68^{*}$ & $0.67^{*}$ \\
Perimeter-area ratio (area-weighted mean) & Vulnerability index & $0.65^{*}$ & $0.72^{*}$ & $0.66^{*}$ & $0.65^{*}$ & 0.56 \\
\hline
\end{tabular}

$* p<0.05 ; * * p<0.01$ 
and abundance. Species that are sensitive to alterations to their habitats occurred more frequently in olive groves surrounded by a landscape that includes a high percentage of natural or semi-natural habitats, although species adapted to human altered habitats were always the most frequent and abundant. The intensity of human activity in an area is also associated with extremely low or negative values of the community vulnerability index in such areas (Scalercio et al., 2007a).

Species richness was low at all the sites sampled and was not associated with the percentage of woodlands and grasslands or any other attribute of the local landscape. In contrast, some species traits were more strongly associated with landscape attributes depending on the spatial scale. The positive correlation between abundance of woodland species and the percentage of woodland within a $1000 \mathrm{~m}$ radius might indicate that woodland has an effect on woodland species only at large spatial scale, as observed also by Bergman et al. (2004), while other factors might dominate the pattern at smaller spatial scales. The positive correlation between species and individuals with low dispersal ability and the percentage of grassland at small spatial scales is probably due to the attractive power of grasslands as foraging areas for butterflies and as a consequence Lepidoptera are more abundant in this habitat. Further studies are needed to confirm these patterns.

Life-history traits are known to determine the responses of plants to forest habitat fragmentation (Kolb \& Diekmann, 2005) and habitat quality has a stronger effect on species composition and life-history traits than on species richness (Aviron et al., 2007). Several authors have successfully used life-history traits for evaluating the sensitivity of insect communities to landscape changes; examples include: risk of extinction of butterflies and moths as a consequence of climate change (Franzén \& Johannesson, 2007), conservation interest of species and communities in mosaic landscapes (Barbaro \& van Halder, 2009) and functional diversity in agro-ecosystems (Tscharntke et al., 2008). Life-history traits such as habitat specialisation, body size and family identity can explain differences in density-area relationships in butterflies and moths (Hambäck et al., 2007). Several studies on the effect of climate change on insect communities highlight the negative affects it has on habitat-specialists, those that disperse slowly and monophagous species, while less demanding species increasingly dominate lepidopteran communities (Warren et al., 2001; Wilson et al., 2007; Barbaro \& van Halder, 2009). In our study, individual ecological traits showed important relationships with some landscape metrics, but only in few cases. The community vulnerability index is more strongly associated with landscape metrics than any other attribute of Lepidoptera communities. Unlike abundance and species richness, the community vulnerability index is associated with all the landscape attributes and at all spatial scales measured. This result suggests that habitat heterogeneity and abundance of ecotones are crucial for the survival of ecologically demanding (i.e. vulnerable) communities of butterflies and moths, and that the community vulnerability index, used in a joint analysis of main ecological traits, is more likely to reveal the influence of landscape than an individual ecological trait.

Prior to using species traits in ecological studies it is important to define them objectively and precisely. Large datasets of the distribution and abundance of species are the starting points for categorising species, but unfortunately they are only available for a few geographical areas and butterflies (see Shreeve et al., 2001). In this study we used rather coarse categories because in some cases, mainly moths, the ecological traits of species are poorly known. There is a need to increase our knowledge of the ecological traits of species in order to refine the descriptive power of communities. One difficulty is the ecological plasticity of species, especially those whose ecology varies greatly throughout their distribution. Samples of Lepidoptera were collected in olive groves, set in landscapes consisting of mainly agricultural land under arable or permanent crops. In particular, the species richness and abundance of woodland specialists and species with poor dispersal ability are negatively associated with the extent of arable land, but none of these correlations were statistically significant (data not shown). This is probably due to the relatively small size of the sample analyzed, which indicates there is a need to determine whether these trends occur larger samples.

Larval diet did not appear to be influenced by any landscape attribute. This may be due to grouping species in a feeding category only on the basis of plant systematics. Probably it would be more appropriate to group species into homogeneous categories based on biochemistry. For example, there is surely a big difference between polyphagous species feeding on Quercus-Carpinus-Acer, or Poa-Carex-Dactylis (all trees/grasses, with very similar leaf biochemistry, despite their taxonomic differences) and those feeding on Mandragora-Solanum-Arum, which chemically are very different plants.

In order to conserve communities with high ecological requirements our results indicate that is important to protect a sufficiently large area and diversity of habitats, especially natural and semi-natural habitats, which may also help species adapt to changes, even in greatly modified landscapes. This is particularly important in the Mediterranean Basin where the level of endemicism is high and hence conservation of these species is of global importance. Ecological traits of species provide better descriptions of the relations between coenosis and attributes of landscape, than species richness. Furthermore, assemblages of Lepidoptera with high ecological requirements seem to be associated with landscape characteristics at different spatial scales, which indicate the importance of landscape-scale studies for the conservation of butterflies and moths.

ACKNOWLEDGEMENTS. We thank D. Guidotti for assistance with the GIS analyses. Thanks to M.E. Noce, V. Vizzarri and $T$. Belfiore for their help with the sampling. We thank farmers for allowing us to access their plots. This study was undertaken within the RIOM project (Ricerca e Innovazione per 
l'Olivicoltura Meridionale) funded by the Italian Ministry of Agriculture.

\section{REFERENCES}

ALtieri M.A. 1999: The ecological role of biodiversity in agroecosystems. Agr. Ecosyst. Environ. 74: 19-31.

Aviron S., Jeanneret P., Schüpback B. \& Herzog F. 2007: Effects of agri-environmental measures, site and landscape conditions on butterfly diversity of Swiss grassland. Agr. Ecosyst. Environ. 122: 295-304.

BALletto E. \& KudRNA O. 1985: Some aspects of the conservation of butterflies in Italy, with recommendations for a future strategy (Lepidoptera, Hesperiidae and Papilionoidea). Boll. Soc. Entomol. Ital. 117: 39-59.

Barbaro L. \& van Halder I. 2009: Linking bird, carabid beetle and butterfly life-history traits to habitat fragmentation in mosaic landscapes. Ecography 32: 321-333.

Beneš J., Kuras T. \& KonvičKa M. 2000: Assemblages of mountainous day-active Lepidoptera in the Hrubý Jeseník Mts, Czech Republic. Biologia 55: 153-161.

Benton T.G., Vickery J.A. \& WiLson J.D. 2003: Farmland biodiversity: is habitat heterogeneity the key? Trends Ecol. Evol. 18: $182-188$

Bergman K.-O., Askling J., Ekberg O., Ignel H., Wahlman H. \& Milberg P. 2004: Landscape effects on butterfly assemblages in an agricultural region. Ecography 27: 619-628.

Berio E. 1985: Fauna d'Italia. Lepidoptera Noctuidae. I. Generalità Hadeninae Cucullinae. Calderini Editore, Bologna, Italy, $1030 \mathrm{pp}$.

Berio E. 1991: Lepidoptera Noctuidae. II. Sezione Quadrifide. Calderini Editore, Bologna, 734 pp.

Bertaccini E., Fiumi G. \& Provera P. 1995: Bombici e Sfingi d'Italia (Lepidoptera, Heterocera). Vol. 1. Natura-Giuliano Russo Editore, Bologna, 248 pp.

Bertaccini E., Fiumi G. \& Provera P. 1997: Bombici e Sfingi d'Italia (Lepidoptera, Heterocera). Vol. 2. Natura-Giuliano Russo Editore, Bologna, 256 pp.

Boccaccio L. \& Petacchi R. 2009: Landscape effects on the complex of Bactrocera oleae parasitoids and implications for conservation biological control. Biocontrol 54: 607-616.

Brussaard L., de Rutter P.C. \& Brown G.G. 2007: Soil biodiversity for agricultural sustainability. Agr. Ecosyst. Environ. 121: 233-244.

Bullock J.M., Pywell R.F., Burke M.J.W. \& Walker K.J. 2001: Restoration of biodiversity enhances agricultural production. Ecol. Lett. 4: 185-189.

CARLSON A. 2000: The effect of habitat loss on a deciduous forest specialist species: the white-backed whoodpecker (Dendrocopos leucotos). Forest Ecol. Manag. 131: 215-221.

Clough Y., Kruess A., Kleisn D. \& TscharntKe T. 2005: Spider diversity in cereal fields: comparing factors at local, landscape and regional scales. J. Biogeogr. 32: 2007-2014.

Collinge S.K. \& Palmer T.M. 2002: The influences of patch shape and boundary contrast on insect response to fragmentation in California grasslands. Landsc. Ecol. 2002: 647-656.

Colwell R.K. 2005: EstimateS: Statistical Estimation of Species Richness and Shared Species from Samples. Version 7.5. http://viceroy.eeb.uconn.edu/estimates. Accessed 20 February 2008.

Devictor V., Romain J. \& Jiguet F. 2008: Distribution of specialist and generalist species along spatial gradients of habitat disturbance and fragmentation. Oikos 117: 507-514.

Diekötter T., Billeter R. \& Crist T.O. 2008: Effects of landscape connectivity on the spatial distribution of insect diver- sity in agricultural mosaic landscapes. Basic Appl. Ecol. 9: 298-307.

Dover J. \& Settele J. 2009: The influences of landscape structure on butterfly distribution and movement: a review. $J$. Insect Conserv. 13: 3-27.

ESRI 2003: ArcGIS 8. Redlands, CA, USA

Fiedler A.K., Landis D.A. \& Wratten S.D. 2008: Maximising ecosystem services from conservation biological control: the role of habitat management. Biol. Control 45: 254-271.

FranzÉn M. \& JohanNESSON M. 2007: Predicting extinction risk of butterflies and moths (Macrolepidoptera) from distribution patterns and species characteristics. J. Insect Conserv. 11: 367-390.

Grill A., Knoflach B., Cleary D.F.R. \& Kati V. 2005: Butterfly, spider, and plant communities in different land-use types in Sardinia, Italy. Biodivers. Conserv. 14: 1281-1300.

Hambäck P.A., Summerville K.S., Steffan-Dewenter I., Krauss J., Englund G. \& Crist O.T. 2007: Habitat specialisation, body size, and family identity explain lepidopteran density-area relationships in a cross-continental comparison. P. Natl. Acad. Sci. USA 104: 8368-8373.

Hausmann A. 2001: The Geometrid Moths of Europe. Vol. 1 (Introduction; Archiearinae, Orthostixinae, Desmobathrinae, Alsophilinae, Geometrinae). Apollo Books, Stenstrup, 282 pp.

Hausmann A. 2004: The Geometrid Moths of Europe. Vol. 2 (Sterrhinae). Apollo Books, Stenstrup, 600 pp.

HaWlena D. \& Bouskila A. 2006: Land management practices for combating desertification cause replacement of desert lizards. J. Appl. Ecol. 43: 701-709.

Holzschun A., Steffan-Dewenter I. \& Tscharntke T. 2008: Agricultural landscapes with organic crops support higher pollinator diversity. Oikos 117: 354-361.

HUNTER M.D. 2002: Landscape structure, habitat fragmentation, and the ecology of insects. Agr. Forest Entomol. 4: 159-166.

JACKSON L.E., PAScual U. \& Hodgkin T. 2007: Utilizing and conserving agrobiodiversity in agricultural landscapes. Agr. Ecosyst. Environ. 121: 196-210.

Julliard R., Jiguet F. \& Couvet D. 2003: Common birds facing global changes: what makes a species at risk? Glob. Change Biol. 10: 148-154.

Kolb A. \& Diekmann M. 2005: Effects of life-history traits on responses of plant species to forest fragmentation. Conserv. Biol. 19: 929-938.

Krauss J., Klein A.M., Steffan-Dewenter I. \& Tscharntke T. 2004: Effects of habitat area, isolation, and landscape diversity on plant species richness of calcareous grasslands. Biodivers. Conserv. 13: 1427-1439.

Krauss J., Steffan-Dewenter I. \& Tscharntke T. 2003: How does landscape context contribute to effects of habitat fragmentation on diversity and population density of butterflies? J. Biogeogr. 30: 889-900.

KRUESS A. 2003: Effects of landscape structure and habitat type on a plant-herbivore-parasitoid community. Ecography 26: 283-290.

MagurRan A.E. 1988: Ecological Diversity and its Measurement. Croom Helm, London, 192 pp.

McGarigal K., Cushman S.A., Neel M.C. \& Ene E. 2002: FRAGSTATS: Spatial Pattern Analysis Program for Categorical Maps. Computer software program produced by the authors at the University of Massachusetts, Amherst. www.umass.edu/landeco/research/fragstats/fragstats.html. Accessed 1 February 2009.

Mennechez G., Schtickzelle N. \& Baguette M. 2003: Metapopulation dynamics of the bog fritillary butterfly: comparison of demographic parameters and dispersal between a 
continuous and a highly fragmented landscape. Landsc. Ecol. 18: $279-291$

Mironov V. 2003: The Geometrid Moths of Europe. Vol. 4 (Larentiinae II: Perizomini and Eupitheciini). Apollo Books, Stenstrup, $464 \mathrm{pp}$.

Munday P.L. 2004: Habitat loss, resource specialisation and extinction on coral reefs. Glob. Change Biol. 10: 1642-1647.

Musters C.J.M., van Alebeek F., Geers R.H.E.M., Korevaar H., Visser A. \& DE SNoo G.R. 2009: Development of biodiversity in field margins recently taken out of production and adjacent ditch banks in arable areas. Agr. Ecosyst. Environ. 129: $131-139$.

NAVeh Z. \& Whittaker R.H. 1980: Structural and floristic diversity of shrublands and woodlands in Northern Israel and other Mediterranean areas. Plant Ecol. 41: 171-190.

Parenzan P. 1994: Contributi alla conoscenza della Lepidotterofauna dell'Italia meridionale. XVII. Geometridae. Entomologica 28: 99-246.

Pollard E. \& Yates T.J. 1993: Monitoring Butterflies for Ecology and Conservation. Chapmann \& Hall, London, 274 pp.

Polus E., Vandewoestijne S., Choutt J. \& Baguette M. 2007: Tracking the effects of one century of habitat loss and fragmentation on calcareous grassland butterfly communities. Biodivers. Conserv. 16: 3423-3436.

Roland J., Keyghobadi N. \& Fownes S. 2000: Alpine Parnassius butterfly dispersal: effects of landscape and population size. Ecology 81: 1642-1653.

Roschewitz I., Hücker M., Tscharntke T. \& Thies C. 2005: The influence of landscape context and farming practices on parasitism of cereal aphids. Agr. Ecosyst. Environ. 108: 218-227.

Rossi J.-P. \& VAN HALDER I. 2010: Towards indicators of butterfly biodiversity based on a multiscale landscape description. Ecol. Indicators 10: 452-458.

RundLöF M. \& SMith H.G. 2006: The effect of organic farming on butterfly diversity depends on landscape context. J. Appl. Ecol. 43: 1121-1127.

Scalercio S., Pizzolotto R. \& Brandmayr P. 2007a: Multiscale analysis of butterfly diversity in a Mediterranean mountain landscape: mapping and evaluation of community vulnerability. Biodivers. Conserv. 16: 3463-3479.

Scalercio S., IAnNotta N. \& Brandmayr P. 2007b: The role of semi-natural and abandoned vegetation patches in sustaining lepidopteran diversity in an organic olive orchard. Bull. Insectol. 60: 13-22.

Schtickzelle N., Mennechez G. \& Baguette M. 2006: Dispersal depression with habitat fragmentation in the bog fritillary butterfly. Ecology 87: 1057-1065.

Shreeve T.G., Dennis R.L.H., Roy D.B. \& Moss D. 2001: An ecological classification of British butterflies: Ecological attributes and biotope occupancy. J. Insect Conserv. 5: $145-161$.

Simon S., Defrance H. \& Sauphanor B. 2007: Effect of codling moth management on orchard arthropods. Agr. Ecosyst. Environ. 122: 340-348.
Stefanescu C., Herrando S. \& PÁramo F. 2004: Butterfly species richness in the north-west Mediterranean Basin: the role of natural and human-induced factors. J. Biogeogr. 31: 905-915.

Summerville K.S. \& CRIST T.O. 2004: Contrasting effects of habitat quantity and quality on moth communities in fragmented landscapes. Ecography 27: 3-12.

Thies C., Steffan-Dewenter I. \& Tscharntke T. 2003: Effects of landscape context on herbivory and parasitism at different spatial scales. Oikos 101: 18-25.

Thomas C.D., Jordano D., Lewis O.T., Hill J.K., Sutcliffe O.L. \& Thomas J.A. 1998: Butterfly distributional patterns, processes, and conservation. In Mace G.M., Balmford A. \& Ginsberg J.R. (eds): Conservation in a Changing World. Cambridge University Press, pp. 107-138.

Thuiller W., Lavorel S. \& AraúJo M.B. 2005: Niche properties and geographical extent as predictors of species sensitivity to climate change. Glob. Ecol. Biogeogr. 14: 347-357.

Tscharntke T., Sekercioglu C.H., Dietsch T.V., Sodhi N.S., HoEhN P. \& Tylianakis J.M. 2008: Landscape constraints on functional diversity of birds and insects in tropical agroecosystems. Ecology 89: 944-951.

Tscharntke T., Klein A.M., Kruess A., Steffan-Dewenter I. \& THIES C. 2005: Landscape perspectives on agricultural intensification and biodiversity - ecosystem service management. Ecol. Lett. 8: 857-874.

Usher M.B. \& KeILLER S.W.J. 1998: The macrolepidoptera of farm woodlands: determinants of diversity and community structure. Biodivers. Conserv. 7: 725-748.

van SwaAy C., Warren M. \& LoÏs G. 2006: Biotope use and trends of European Butterflies. J. Insect Conserv. 10: 189-209.

VArgas J.M., Guerrero J.C. \& ReAL R. 2004: Effects of natural phenomena and human activity on the species richness of endemic and non-endemic Heteroptera in the Canary Islands. Anim. Biodivers. Conserv. 27: 57-66.

Warren M.S., Hill J.K. \& Thomas J.A. 2001: Rapid responses of British butterflies to opposing forces of climate and habitat change. Nature 414: 65-69.

Westphal C., Steffan-Dewenter I. \& Tscharntke T. 2006: Bumblebees experience landscapes at different spatial scales: possible implications for coexistence. Oecologia 149: 289-300.

Wilson R.J., Gutiérrez D., Gutiérrez J. \& Monserrat V.J. 2007: An elevational shift in butterfly species richness and composition accompanying recent climate change. Glob. Change Biol. 13: 1873-1887.

Zaller J., Moser D., Drapela T., Schmöger C. \& Frank T. 2008: Effect of within-field and landscape factors on insect damage in winter oilseed rape. Agr. Ecosyst. Environ.123: 233-238.

Received August 26, 2011; revised and accepted December 12, 2011 
APPENDIX 1. List of species sampled, their ecological traits and abundance expressed in terms of the number of individuals recorded at each site sampled. Dispersal ability $(\mathrm{L}=$ low, $\mathrm{M}=$ medium, $\mathrm{H}=$ high$)$, habitat preference $(\mathrm{W}=$ woodland, $\mathrm{E}=\mathrm{ecotone}$, $\mathrm{G}=$ grassland, Gen = generalist $)$ and host-plant specificity (Mon = monophagous, Oli = oligophagous, Pol = polyphagous). Nomenclature follows Fauna Europaea vers. 2.4 (www.faunaeur.org).

Species

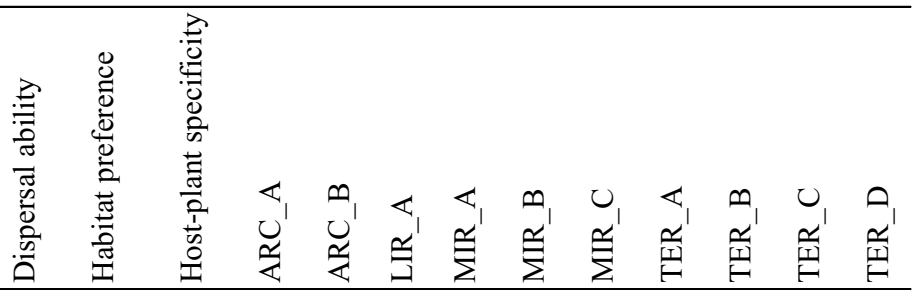

HESPERIIDAE

Carcharodus alceae (Esper, 1780)

Gegenes pumilio (Hoffmannsegg, 1804)

Ochlodes sylvanus (Esper, 1777)

Muschampia proto (Ochsenheimer, 1808)

Spialia sertorius (Hoffmannsegg, 1804)

Thymelicus acteon (Rottemburg, 1775)

PAPILIONIDAE

Iphiclides podalirius (Linnaues, 1758)

Papilio machaon Linnaues, 1758

PIERIDAe

Colias croceus (Fourcroy, 1785)

Gonepteryx cleopatra (Linnaues, 1767)

Pieris brassicae (Linnaues, 1758)

Pieris manni (Mayer, 1851)

Pieris napi (Linnaues, 1758)

Pieris rapae (Linnaues, 1758)

Pontia daplidice (Linnaues, 1758)

LyCAENIDAE

Aricia agestis (Denis \& Schiffermuller, 1775)

Cacyreus marshalli Butler, 1898

Lampides boeticus (Linnaues, 1767)

Lycaena phlaeas (Linnaues, 1761)

Lycaena tityrus Poda, 1761

Polyommatus icarus (Rottemburg, 1775)

Syntharucus pirithous (Linnaues, 1767)

NyMPHALIDAE

Argynnis pandora (Denis \& Schiffermuller, 1775)

Argynnis paphia (Linnaues, 1758)

Coenonympha pamphilus (Linnaues, 1758)

Hipparchia semele (Linnaues, 1758)

Hipparchia statilinus (Hufnagel, 1766)

Lasiommata megera (Linnaues, 1767)

Maniola jurtina (Linnaues, 1758)

Melitaea cinxia (Linnaues, 1758)

Pararge aegeria (Linnaues, 1758)

Pyronia cecilia (Vallantin, 1894)

Vanessa atalanta (Linnaues, 1758)

Vanessa cardui (Linnaues, 1758)

GeOMETRIDAE

Camptogramma bilineata (Linnaues, 1758)

Coenotephria salicata (Denis \& Schiffermuller, 1775)

Cyclophora ruficiliaria (Herrich-Schaffer, 1855)

Epirrhoe alternata (Muller, 1764)

Eupithecia centaureata (Denis \& Schiffermuller, 1775)

Eupithecia ericeata (Rambur, 1833)

Eupithecia innotata (Hufnagel, 1767)

$\begin{array}{ccccccccccccc}\text { L } & \text { E } & \text { Oli } & 1 & 1 & . & . & 2 & 1 & 1 & 1 & . & 1 \\ \text { M } & \text { G } & \text { Oli } & . & . & . & 2 & 1 & . & . & 12 & 2 & 1 \\ \text { L } & \text { E } & \text { Oli } & 1 & 3 & 4 & . & 3 & . & 1 & . & 2 & . \\ \text { L } & \text { G } & \text { Mon } & . & . & . & 3 & . & . & 2 & 1 & 4 & . \\ \text { M } & \text { G } & \text { Pol } & . & . & . & 1 & 1 & . & . & 1 & . & . \\ \text { L } & \text { G } & \text { Oli } & . & . & . & 1 & . & . & . & . & . & .\end{array}$

$\begin{array}{cccccccccccc}\text { M } & \text { E } & \text { Oli } & . & . & . & . & . & . & 1 & . & 1 \\ \mathrm{H} & \mathrm{G} & \text { Oli } & 6 & 1 & 6 & 2 & 1 & . & 4 & 11 & 12\end{array}$.

$\begin{array}{lllllllllllll}\mathrm{H} & \text { Gen } & \text { Oli } & 10 & 12 & 14 & 4 & 12 & 3 & 5 & 11 & 15 & 3\end{array}$

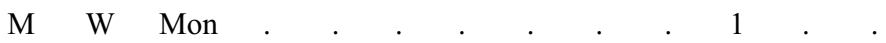

$\begin{array}{lllllllllllll}\mathrm{H} & \text { Gen } & \text { Oli } & 19 & 14 & 16 & 30 & 12 & 45 & 55 & 67 & 46 & 20\end{array}$

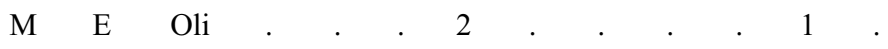

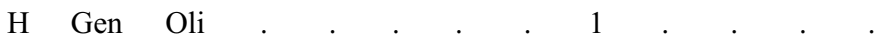

$\begin{array}{llllllllllll}\mathrm{H} & \mathrm{Gen} & \mathrm{Oli} & . & & . & 6 & 5 & 2 & 7 & 12 & 9\end{array}$

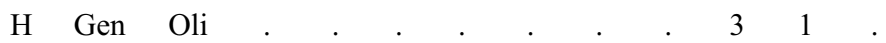

$\begin{array}{ccccccccccccc}\text { M } & \text { G } & \text { Oli } & 1 & . & . & . & . & . & . & . & . & . \\ \text { H } & \text { Gen } & \text { Oli } & . & . & 1 & 1 & . & . & . & . & . & . \\ \text { H } & \text { E } & \text { Oli } & 1 & . & 1 & . & . & 2 & 1 & 3 & . & . \\ \text { M } & \text { E } & \text { Oli } & . & . & . & . & 2 & 1 & . & 2 & 5 & . \\ \text { M } & \text { E } & \text { Mon } & . & . & . & . & 1 & . & . & . & . & . \\ \text { M } & \text { Gen } & \text { Oli } & 2 & 1 & 4 & 7 & 4 & . & 6 & 11 & 7 & . \\ \text { H } & \text { Gen } & \text { Oli } & . & . & . & . & 1 & . & . & . & . & .\end{array}$

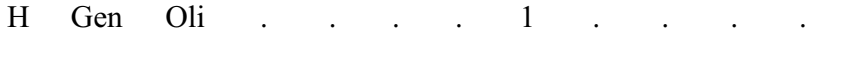

$\begin{array}{lcccccccccccc}\text { M } & \text { W } & \text { Oli } & 2 & 2 & 3 & 1 & . & . & 4 & 5 & 7 & . \\ \text { M } & \text { W } & \text { Oli } & 1 & . & . & . & . & . & . & . & . & . \\ \text { M } & \text { G } & \text { Oli } & . & 2 & 7 & 4 & 5 & 1 & . & 1 & 1 & . \\ \text { M } & \text { G } & \text { Oli } & . & 1 & . & . & . & . & . & . & . & . \\ \text { L } & \text { G } & \text { Oli } & . & . & . & . & . & . & 1 & . & . & . \\ \text { M } & \text { Gen } & \text { Oli } & 50 & 51 & 69 & 54 & 27 & 30 & 54 & 65 & 72 & 3 \\ \text { M } & \text { E } & \text { Oli } & . & . & . & . & 1 & 1 & . & . & 2 & . \\ \text { M } & \text { E } & \text { Oli } & . & 1 & . & . & . & . & . & . & . & . \\ \text { L } & \text { W } & \text { Oli } & 1 & 5 & 4 & 7 & 4 & 4 & 1 & 3 & 3 & . \\ \text { L } & \text { G } & \text { Oli } & 1 & . & 1 & . & . & . & . & 1 & 1 & . \\ \text { H } & \text { Gen } & \text { Pol } & 1 & 1 & 1 & . & . & . & 1 & . & . & . \\ \text { H } & \text { Gen } & \text { Pol } & 2 & 1 & 1 & . & . & 2 & . & 3 & 3 & .\end{array}$

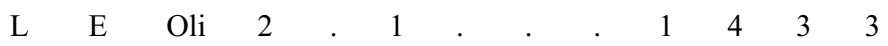

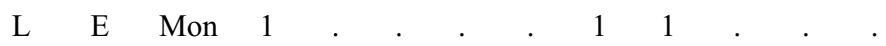

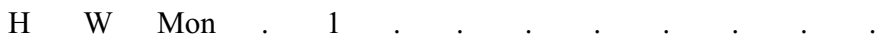

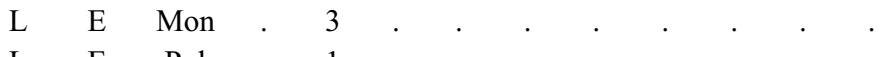

L E Pol

L W Oli

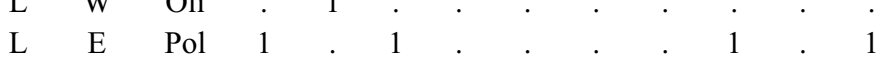


Eupithecia semigraphata Bruand, 1850

Gymnoscelis rufifasciata (Haworth, 1809)

Idaea degenerarla (Hubner, 1799)

Idaea elongaria (Rambur, 1833)

Idaea filicata (Hubner, 1799)

Idaea infirmarla (Rambur, 1833)

Idaea obsoletaria (Rambur, 1833)

Idaea seriata (Schrank, 1802)

Idaea subsericeata (Haworth, 1809)

Larentia malvata (Rambur, 1833)

Menophra japygiaria (O. Costa, 1809)

Peribatodes rhomboidaria (Denis \& Schiffermuller, 1775)

Rhodometra sacraria (Linnaues, 1767)

Scopula marginepunctata (Goeze, 1781)

Scopula minorata (Boisduval, 1833)

Synopsia sociaria (Hubner, 1799)

Timandra comae Schmidt, 1931

Noctuidae

Acontia trabealis (Scopoli, 1763)

Acronicta rumicis (Linnaeus, 1758)

Agrochola circellaris (Hufnagel, 1766)

Agrochola helvola (Linnaeus, 1758)

Agrochola lota (Clerck, 1759)

Agrochola lychnidis (Denis \& Schiffermuller, 1775)

Agrotis puta (Hubner, 1803)

Agrotis segetum (Denis \& Schiffermuller, 1775)

Agrotis trux (Hubner, 1824)

Amphipyra pyramidea (Linnaeus, 1758)

Autographa gamma (Linnaeus, 1758)

Caradrina clavipalpis Scopoli, 1763

Chrysodeixis chalcites (Esper, 1789)

Cryphia ochsi (Boursin, 1940)

Cryphia algae (Fabricius, 1775)

Dysgonia algira (Linnaeus, 1767)

Helicoverpa armigera (Hubner, 1808)

Heliothis peltigera (Denis \& Schiffermuller, 1775)

Hoplodrina ambigua (Denis \& Schiffermuller, 1775)

Hypena lividalis (Hubner, 1796)

Leucania loreyi (Duponchel, 1827)

Macdunnoughia confusa (Stephens, 1850)

Mniotype solieri (Boisduval, 1829)

Mythimna unipuncta (Haworth, 1809)

Nodaria nodosalis (Herrich-Schaffer, 1851)

Pechipogo plumigeralis Hubner, 1825

Peridroma saucia (Hubner, 1808)

Rivula sericealis (Scopoli, 1763)

Schrankia costaestrigalis (Stephens, 1834)

Spodoptera cilium Guenée, 1852

Spodoptera exigua (Hubner, 1808)

Thysanoplusia circumscripta (Freyer, 1831)

Thysanoplusia daubei (Boisduval, 1840)

Tyta luctuosa (Denis \& Schiffermuller, 1775)

Xestia xanthographa (Denis \& Schiffermuller, 1775)

ArctiIDAe

Dysauxes famula (Freyer, 1836)

Eilema caniola (Hubner, 1808)

$\begin{array}{ccccccccccccc}\text { L } & \text { Gen } & \text { Oli } & 1 & 2 & 1 & . & . & . & . & . & . & 1 \\ \text { M } & \text { Gen } & \text { Pol } & . & 2 & 1 & . & . & . & 4 & 8 & 1 & . \\ \text { M } & \text { Gen } & \text { Pol } & 1 & 1 & 1 & 1 & . & . & . & . & . & . \\ \text { M } & \text { E } & \text { Pol } & . & . & . & . & 1 & 1 & 3 & 1 & 1 & . \\ \text { M } & \text { E } & \text { Pol } & 1 & 6 & 1 & 2 & . & 1 & . & 4 & 2 & 1 \\ \text { M } & \text { E } & \text { Pol } & . & . & . & . & . & . & . & 1 & 1 & . \\ \text { H } & \text { E } & \text { Pol } & . & 1 & 1 & 1 & . & 1 & 1 & 5 & 6 & . \\ \text { H } & \text { Gen } & \text { Pol } & 3 & 2 & 3 & 1 & 2 & . & 3 & 5 & 8 & . \\ \text { M } & \text { E } & \text { Pol } & 1 & 5 & . & . & . & . & . & . & 1 & . \\ \text { L } & \text { E } & \text { Oli } & . & . & . & . & . & . & 1 & . & . & . \\ \text { L } & \text { E } & \text { Mon } & . & . & . & . & 1 & . & . & 1 & 1 & 1 \\ \text { H } & \text { Gen } & \text { Pol } & . & . & . & . & . & . & . & 2 & 1 & . \\ \text { H } & \text { G } & \text { Oli } & . & . & . & . & 1 & . & . & . & . & . \\ \text { H } & \text { Gen } & \text { Pol } & . & 1 & . & 2 & . & 1 & 1 & 1 & . & 3 \\ \text { H } & \text { G } & \text { Pol } & 1 & 2 & . & 1 & 4 & 3 & 5 & 25 & 6 & 2 \\ \text { M } & \text { E } & \text { Pol } & . & 1 & . & . & . & . & . & . & . & . \\ \text { M } & \text { E } & \text { Oli } & 1 & . & . & . & 1 & 1 & . & . & 1 & .\end{array}$

